\title{
The Role of Organic Carbon in Natural and Synthetic Oestrogens Sorption onto Soils
}

\author{
E. A. Aziz, W. A. Wan Omar, N. A. Zainodin, and Mir Sujaul Islam
}

\begin{abstract}
Among the compounds implicated as Environmental Endocrine Disruptors (EEDs), the most potent to alter the normal functions of the endocrine systems of organisms and humans are the natural and synthetic oestrogen. They are hydrophobic and ubiquitous and remain in the final effluents for the vast majority of sewage treatment plant. Land application of animal manures and sewage sludge as fertilizers has been reported to increase the amount of hormones in soil. However, the information on the factor that influences the occurrence of these compounds in this environmental compartment is limited. This study investigates the sorption affinity of these oestrogens on soils by determining its soil-water partition coefficient $\left(K_{d}\right)$, sorption coefficient normalised to organic carbon $\left(K_{o c}\right)$ and octanol-water partition coefficient $\left(K_{o w}\right)$. In this study, different percentage of organic carbon was used. The results obtained shows that the $K_{o w}$ is a good predictor of sorption among contaminants as the affinity of oestrogens in soils is strongly dependent to their $K_{o w}$ values. This study also shows that the solid-water partition coefficient $\left(K_{d}\right)$ of all oestrogens have good correlation to the organic carbon content. The calculated sorption coefficient normalised to organic carbon $\left(K_{o c}\right)$ indicate a strong association of all oestrogens with organic carbon. Therefore it is concluded that the organic carbon is pertinent to the sorption of oestrogens in soils.
\end{abstract}

Index Terms-Octanol-water partition coefficient $\left(K_{o w}\right)$, solid-water partition coefficient $\left(K_{d}\right)$, sorption coefficient normalised to organic carbon $\left(K_{o c}\right)$, organic carbon, sorption affinity.

\section{INTRODUCTION}

Steroidal hormones are relatively the most potent endocrine disrupters that may interfere the normal functions of the endocrine systems [1]. The most active oestrogens hormones which are secreted by the ovaries in woman of normal menstrual cycles and by the placenta in pregnant woman along with its metabolite oestrone is $17 \beta$-oestradiol. This naturally hormones are also being secreted by male as well as animals. Meanwhile, $17 \alpha$-ethnyloestradiol (EE2) is one of the synthetic oestrogens which commonly used for oestrogen replacement therapy particularly in oral contraceptives formulations and hormone replacement

Manuscript received April 25, 2015; revised July 3, 2015. This work was supported by Ministry of Higher Education (MOHE) Malaysia with the grant FRGS/RDU130102.

E. A. Aziz and N. A. Zainodin are with the University Malaysia Pahang, Lebuhraya Tun Razak, 26300 Kuantan, Pahang, Malaysia (e-mail: edriyana@ump.edu.my, nurulain@yahoo.com.my).

W. A. Wan Omar was with University Malaysia Pahang. She is now with Mara Polythecnic College University, Kuantan, Pahang Malaysia (e-mail: wan atikah@yahoo.com.my).

Mir Sujaul Islam was with National University of Malaysia (UKM). He is now with University Malaysia Pahang, Lebuhraya Tun Razak, 26300 Kuantan, Pahang, Malaysia (e-mail: mirsujaulislam@ump.edu.my). therapy.

In the recent past, several studies reported detection of steroidal hormones at the surface waters and it has been revealed that even at $1 \mathrm{ng} / \mathrm{l}$ of $17 \beta$-Oestradiol (E2), it is able to reduce sperm fertility drastically as well as induce vitellogenin in male trout [1]. Previous researches show that the occurrences of steroidal hormones at surface water largely contributed from the incomplete removal in municipal wastewater treatment plant. The degrees to which contaminants from wastewater present a risk to human health depend on their concentration, mobility and fate to human receptors. As the steroidal hormones in aquatic environment has been extensively carried out unfortunately a very few study concerns to terrestrial organisms.

The exposure of soil to steroidal oestrogens is believed to occur from several sources such as land application of sewage reuse and animal manure and leaking from onsite sewage treatment. However, soil samples have largely been overlooked and the information on this environmental compartment is limited in the literature. Nevertheless, there is still evidence on the occurrence of these steroidal oestrogens in soils. Finlay Moore reported the detection of $17 \beta$-Oestradiol (E2) in a pasture topsoil $(0-2.5 \mathrm{~cm})$ after 4 days amendment with poultry litter with a concentration of $305-820 \mathrm{ngL}^{-1}$ and after 88 days it was still detected in the range between 60-125 $\mathrm{ngL}^{-1}$ [2]. Meanwhile, Beck recently reported the concentration of oestrogens in the ranges between $3 \mathrm{ngkg}^{-1}$ and $25 \mathrm{ngkg}^{-1}$ for $17 \beta$-Oestradiol (E2) and Oestrone (E1) in a cropland soil that had been regularly amended with manure three times a year, and $2 \mathrm{ngkg}^{-1}$ and 12 $\mathrm{ngkg}^{-1}$ respectively in an intensively grazed pasture soil (0-15 $\mathrm{cm})$ which was also amended with manure [3]. A few studies reported that disposal of animal manure to agricultural land could lead to movement of these compounds into groundwater [4], [5]. Shore believed that a constant $17 \beta$-Oestradiol (E2) concentration of about $5 \mathrm{ngL}^{-1}$ is spring waters was caused by infiltration through the soil profile to the groundwater following manure application to land [4]. Peterson in their work to study the impact of disposal of poultry manure by the poultry industry had measured $17 \beta$-Oestradiol (E2) concentrations ranging from 6 to 66 $\mathrm{ngL}^{-1}$ in mantled karst aquifers in Northwest Arkansas, an area where a large segment of the agricultural economy of United States of America is located [5]. Swartz attempted a study to understand the fate of organic sewage contaminants introduced to groundwater by installing a series of sampling wells immediately downgradient from a septic system that discharged sewage effluent to as hallow sandy aquifer of Cape Code, USA and reported the occurrence of $17 \beta$-Oestradiol (E2) and Oestrone (E1) with the concentrations 
approximately $10 \mathrm{ngL}^{-1}$ and $80 \mathrm{ngL}^{-1}$ at $5 \mathrm{~m}$ depth below the wells land surface and suggested that the concentrations detected indicate that the potential groundwater contamination exists [6].

Due to the previous reported this study was initiated so as to understand the pertinent factor influences the presence of these compounds in soils. The objective of this work was to investigate the sorption affinity of these oestrogens on soils organic carbon as well as the relationship between sorption and their physicochemical parameters; octanol-water partition coefficient $\left(K_{o w}\right)$.

\section{MATERIALS AND METHODS}

\section{A. Chemicals}

The molecular structures of the compounds under investigation are shown in Fig. 1.

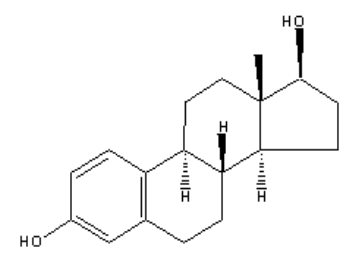

(a) $17 \beta$-Oestradiol (E2)

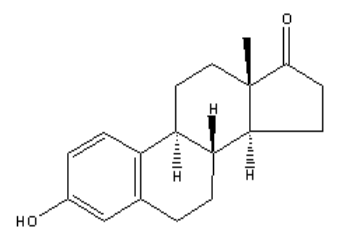

(b) Oestrone (E1)

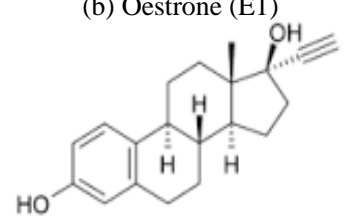

(c) $17 \alpha$-ethnyloestradiol (EE2)

Fig. 1. Molecular structures of 17 $\beta$-Oestradiol (E2), Oestrone (E1), and $17 \alpha$-ethnyloestradiol (EE2).

TABLE I: PHYSICO-CHEMICAL PROPERTIES OF COMPOUNDS UNDER INVESTIGATION

\begin{tabular}{|l|l|l|l|}
\hline & $17 \beta$-oestradiol & Oestrone & $17 \alpha \mathrm{EE}$ \\
\hline $\begin{array}{l}\text { Molecular } \\
\text { Formula }\end{array}$ & $\mathrm{C}_{18} \mathrm{H}_{24} \mathrm{O}_{2}$ & $\mathrm{C}_{18} \mathrm{H}_{22} \mathrm{O}_{2}$ & $\mathrm{C}_{20} \mathrm{H}_{24} \mathrm{O}_{2}$ \\
\hline $\begin{array}{l}\text { Molecular } \\
\text { Weight } \\
(\mathrm{g} / \mathrm{mol})\end{array}$ & 272.37 & 270.36 & 296.39 \\
\hline $\begin{array}{l}\text { Vapour } \\
\text { Pressure } \\
(\text { Pa) }\end{array}$ & $1.26 \times 10^{-8}$ & $1.42 \times 10^{-7}$ & $2.67 \times 10^{-9}$ \\
\hline $\begin{array}{l}\text { Water } \\
\text { Solubility } \\
(\mathrm{mg} / \mathrm{L})\end{array}$ & $3.6^{\mathrm{a}}$ & $30^{\mathrm{a}}$ & $11.3^{\mathrm{a}}$ \\
\hline Log K & & & \\
\hline
\end{tabular}

${ }^{a}$ From EPISUITE

${ }^{\mathrm{b}}$ Results taken from [7], [8] and [9]

All analytical standards; 17 $\beta$-Oestradiol (E2, > 99\% purity), Oestrone (E1, > 99\% purity), 17 $\alpha \mathrm{EE}$ (EE2, $>98 \%$ purity), Napthalene (99\% purity), Anthracene (>99\% purity), Fluoranthene ( $>99.5 \%$ purity), Crysene ( $>95 \%$ purity),
Benzo(a)pyrene (>97\% purity) and Benzoic Acid (>99.5\% purity) were purchased from Sigma Aldrich Ltd, United Kingdom. Acetonitrile (HPLC-Grade) and methanol (HPLC-Grade) were obtained from Fisher Scientific Laboratory, United Kingdom. Table I shows the physicochemical properties of the compounds under investigation.

\section{B. Soils}

Three soils used in this study namely I, II and III were classified as sandy loam (BS 3882:1994 Classification of Top Soil). The organic matter content was recorded to be different from each other. All soils were subjected to several tests in order to obtain their soil properties which accordance to British Standards and American Society Testing Standards [10]-[12].

Organic carbon for all soils was determined in accordance with the ASTM standard D2974-00 [10]. The carbonate content was further assessed through the observation of any bubbles produced on addition of $\mathrm{HCl}$ from $\mathrm{CO}_{2}$ liberated from breakdown of carbonates in the soils [13]. The experiment was negative for all soils. Thus, the total carbon (TC) is considered similar to the organic carbon in all soils [10]. Soil $\mathrm{pH}$ was obtained accordance to the BS 1377-3:1990 [12]. The organic carbon (OC) of soil II, II and III were $8.90 \%, 4.92 \%$, and $1.62 \%$ while the $\mathrm{pH}$ were $5.5,5.5$ and 5.9 respectively.

\section{Solution and Techniques of Analysis}

The stock solutions of each compound were prepared at concentrations of $1000 \mathrm{mg} / \mathrm{l}$ by dissolving in high performance liquid chromatograph HPLC-grade methanol. An initial concentrations solution for sorption experiments were prepared by mixing a desired volume of stock solutions with a background solution in a volumetric flask. The background solution for sorption experiments used was Nanopure water, which is accordance to ASTM E1195-01 Batch Equilibrium Method.

The initial aqueous concentrations were analysed by a reverse phase high performance liquid chromatography (RP-HPLC) with UV/VIS detector. The Allure Biphenyl $5 \mu \mathrm{m}$, $60 \AA, 150 \times 4.6 \mathrm{~mm}$ column was used as an analytical column. The ultra violet (UV) detector was set at a wavelength of $220 \mathrm{~nm}$ for all compounds. The eluting solvent used was a mixture of HPLC-grade Acetonitrile and Nanopure water at ratios of $60: 40(\mathrm{v} / \mathrm{v})$.

\section{EXPERIMENT}

\section{A. Water Solubility Determination}

In a screening sorption experiments, the water solubility of all chemicals were significantly lower than those in the EPI-Suite database as well as in previous literature review. Thus, an experiment to measure solubility under the same conditions as for the sorption experiments was carried out. Six replicate glass vessels $(20 \mathrm{ml})$, each containing excessive solid of each oestrogenic steroid were used for each aqueous solution system. After shaking for 7 days, the vessels were set upright at least 1 day to allow residual organic crystals to accumulate at the bottom. A supernatant from each vessels 
were withdrawn by using a disposable glass pipette and were subjected to analytical procedure to analyse.

\section{B. Sorption Experiment-Octanol-Water Partition Coefficient $\left(K_{\text {ow }}\right)$}

The determination of $\log K_{o w}$ for each oestrogen was obtained by Shake Flask method. This method was in accordance with the Organisation for Economic Co-operation and Development (OECD) guidelines for the testing of chemicals [14]. The experiment was carried out at $20^{\circ} \mathrm{C} \pm 0.1$. In triplicate, each ratio of the individual oestrogens was shaken for 24 hours. Initially, water saturated with n-octanol and n-octanol saturated with water were prepared. In a $25 \mathrm{ml}$ test tube, three ratios of saturated n-octanol:water 1:1, 1:2, and 2:1 were equilibrated with oestrogen at a concentration of $1800 \mathrm{mgL}^{-1}$. After completion of shaking, all tubes were centrifuged for 15 minutes by laboratory centrifuge maintained at $20^{\circ} \mathrm{C} \pm 0.1$. The aqueous phase was withdrawn and analysed by HPLC. The $\mathrm{pH}$ recorded was in the range 6.1 to 6.3 for all solutions.

\section{Sorption Experiment-Solid-Water Partition Coefficient} $\left(K_{d}\right)$

Sorption coefficients of all compounds on soils were measured completely using a batch equilibrium method following laboratory procedure described in ASTM:E 1195-01. The experiments consisted a preliminary as well as a final test. The purpose of preliminary test was to determine an appropriate ratio of solid to solution as well as to obtain the equilibration time for each compound. In this study, sorption of all compounds reached equilibrium within 24 hours which is in agreement with previous study [15], [16].

For each batch equilibrium experiment, each of oestrogen solution was added to $0.25 \mathrm{~g}$ of air-dry soils in duplicates in 25 $\mathrm{ml}$ centrifuge tubes. The initial aqueous concentration of each compound was below the water solubility $\left(S_{w}\right)$ as well as above the limit of detection (LOD) of the analyses Tubes were then placed horizontally on an orbital shaker set at $300 \mathrm{rpm}$ at $20 \pm 0.5^{\circ} \mathrm{C}$ and in the dark. Shaking times were 24 hours as obtained from preliminary test. After equilibration, the tubes were centrifuged at $4000 \mathrm{rpm}$ for 20 minutes. After centrifugation, the supernatants were further filtered through Whatman glass fibre glass $(\mathrm{GF} / \mathrm{C})$. The filtrates were then subjected to HPLC to quantify the concentrations of oestrogens remaining in solutions. The amount of oestrogens sorbed onto soil was determined indirectly by the differences between the initial and equilibrium concentrations. In all experiments, tubes containing no solids were run as a control to assess loss of compounds to the tubes. Blank samples were also conducted simultaneously in order to ensure no other contaminants present in the system.

The sorption coefficients $\left(K_{d}\right)$ and organic carbon normalised sorption coefficient $\left(K_{o c}\right)$ were calculated using the following equations:

$$
\begin{gathered}
q_{e}=K_{d} C_{e} \\
K_{o c}=K_{d} / \% o r g a n i c \text { carbon }
\end{gathered}
$$

where $q_{e}$ is the concentration of compound adsorbed by the soil $(\mathrm{mg} / \mathrm{g})$ and $C_{e}$ is the final aqueous concentration of compounds after equilibration (mg/l).

\section{RESULTS AND DISCUSSION}

\section{A. Water Solubility}

From Table II, it can be seen that the water solubility values for all compounds were lower than the default EPISUITE values and available literature.

TABLE II: COMPARISON OF WATER SOLUBILITY VALUES

TABLE II: COMPARISON OF WATER SOLUBILITY VALUES
\begin{tabular}{|l|c|l|c|}
\hline \multicolumn{4}{|c|}{ Water Solubility $\left(\mathbf{m g L}^{-\mathbf{1}}\right)$} \\
\hline & Exp & EPISUITE & Lit \\
\hline $\begin{array}{l}17 \beta \text {-oestradiol } \\
\left(\mathrm{C}_{18} \mathrm{H}_{24} \mathrm{O}_{2}\right)\end{array}$ & $3.1 \pm 0.02$ & 3.6 & $13.0^{\mathrm{a}}$ \\
\hline $\begin{array}{l}\text { Oestrone } \\
\left(\mathrm{C}_{18} \mathrm{H}_{22} \mathrm{O}_{2}\right)\end{array}$ & $2.1 \pm 0.03$ & 30.0 & $13.0^{\mathrm{a}}$ \\
\hline $\begin{array}{l}17 \alpha \mathrm{EE} \\
\left(\mathrm{C}_{20} \mathrm{H}_{24} \mathrm{O}_{2}\right)\end{array}$ & $3.1 \pm 0.03$ & 11.3 & $4.8^{\mathrm{a}}$ \\
\hline
\end{tabular}
$\begin{aligned} & \text { Results taken from [17] } \\
& \text { Resule }\end{aligned}$

\section{B. Sorption Experiment-Octanol-Water Partition Coefficient $\left(K_{\text {ow }}\right)$}

The $\log K_{o w}$ values for all oestrogens obtained is shown in Table III. The $\log K_{o w}$ values obtained from this method for $17 \beta$-oestradiol (E2) and 17 $\alpha$-ethnyloestradiol (EE2) are lower than default values given by the computational model (Kowwin-EPISUITE) however the experimental $\log K_{o w}$ values for oestrone (E1) was higher. This disparity between the experimental values and values given from the computational model is mainly because the default values given by the computational model (Kowwin-EPISUITE) were estimated from their structural property without accounting for ambient conditions. From this direct measurement of $K_{o w}$ for oestrogens, one clear conclusion can be drawn. Water solubility indicates a strong correlation with hydrophobicity as this method indicate the lowest water solubility oestrogen, oestrone (E1) is the most hydrophobic among them as shown by its highest $\log K_{o w}$ values.

\begin{tabular}{|c|c|c|c|}
\hline \multicolumn{4}{|c|}{ SHAKE FLASK METHOD $(N=9)$} \\
\hline & $\begin{array}{l}\text { Oestrone } \\
\text { (E1) }\end{array}$ & $\begin{array}{l}\text { 17及-oestradiol } \\
\text { (E2) }\end{array}$ & $\begin{array}{l}\text { 17 } \alpha-E E \\
\text { (EE2) }\end{array}$ \\
\hline $\begin{array}{l}\text { Log } \\
\mathbf{K}_{\mathbf{o w}}\end{array}$ & $3.95 \pm 0.03$ & $3.82 \pm 0.02$ & $3.85 \pm 0.02$ \\
\hline
\end{tabular}

TABLE III: MEASURED LOG KOW VALUES OF OESTROGENS OBTAINED FROM

\section{Sorption Experiment-Solid-Water Partition Coefficient $\left(K_{d}\right)$}

In this study, a 24 hour period was required to reach equilibrium of oestrogens in all soils. Equilibrium periods of 24 hours or less have also been reported elsewhere [17]-[19]. For the examination of maximum capacity of oestrogens, a soil-water ratio of 1:250 gave the highest adsorption among the tested ratios however, due to the technical problem in weighing the individual material for soil mixes, a ratio 1 to 100 of soil-water was selected. All tubes were shaken for 24 hours at a constant temperature, $20^{\circ} \mathrm{C} \pm 0.1$ in the dark room and were filtered and pre-concentrated before injected into HPLC for analysis.

The adsorption isotherm for natural and synthetic oestrogens is generally linear over the ranges of concentration 
in all soils used. The linear regression analysis gave $R^{2}>0.97$ for all compounds. From this, the solid-water partition coefficient $\left(K_{d}\right)$ for all oestrogens indicates good correlation to the organic carbon content as shown in Fig. 2. Soil with greater organic matter adsorbed more oestrogens than soils with less organic matter content.

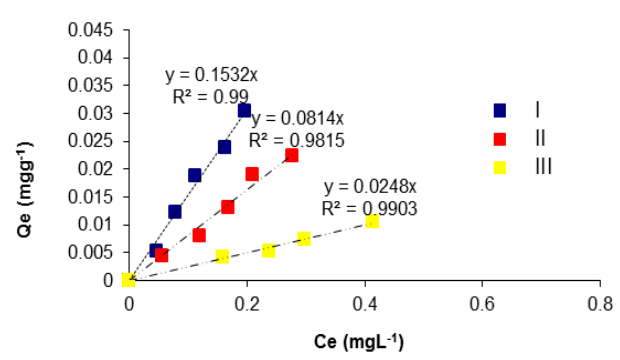

(a)

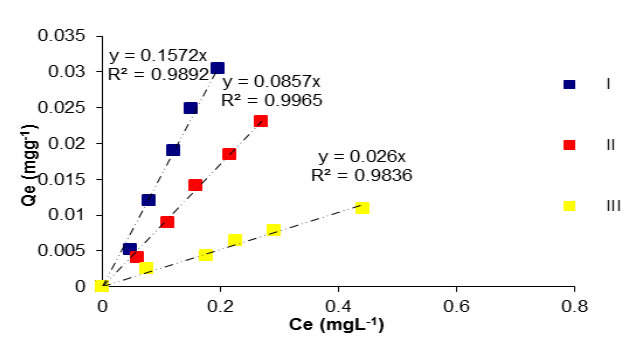

(b)

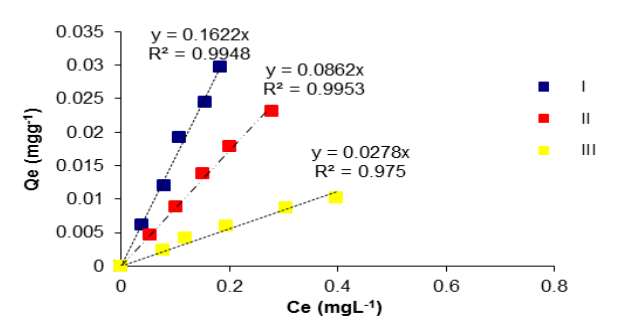

(c)

Fig. 2. Sorption isotherm $\mathrm{f}$ oestrogens in soils (a) $17 \beta$-oestradiol (E2) (b) Oestrone (E1) (c) 17 $\alpha$-ethnyloestradiol (EE2).

\section{Sorption Coefficient Normalised to Organic Carbon} $\left(K_{o c}\right)$

The calculated sorption coefficient normalised to organic carbon $\left(K_{o c}\right)$ is shown in Table IV.

TABLE IV: THE $K_{D}$ AND LOG $K_{O C}$ FOR THE LINEAR ISOTHERM FIT FOR

\begin{tabular}{ccccc}
\multicolumn{5}{c}{ OESTROGENS IN SOILS } \\
\hline Soil & OC \% & $K_{d}\left(\mathrm{Lkg}^{1}\right)$ & $K_{o c}\left(\mathrm{Lkg}^{-1}\right)$ & $\log K_{o c}$ \\
\hline & & & Oestrone (E1) & \\
I & 8.90 & 162.2 & 1822.47 & 3.26 \\
II & 4.92 & 86.2 & 1752.03 & 3.24 \\
III & 1.62 & 27.8 & 1716.05 & 3.23 \\
& & & $\mathbf{1 7 \beta - o e s t r a d i o l}$ & \\
& & & (E2) & \\
I & 8.90 & 153.2 & 1721.35 & 3.24 \\
II & 4.92 & 81.4 & 1654.47 & 3.22 \\
III & 1.62 & 24.8 & 1530.86 & 3.18 \\
& & & $\mathbf{1 7 \alpha -}$ & \\
& & & ethnyloestradiol & \\
& & & $(\mathbf{E E 2})$ & 3.25 \\
I & 8.90 & 157.2 & 1766.29 & 3.24 \\
II & 4.92 & 85.7 & 1741.87 & 3.21 \\
III & 1.62 & 26.0 & 1604.94 & \\
\hline
\end{tabular}

The obtained values indicate a strong association of all oestrogens with organic carbon. $K_{o c}$ value of oestrone (E1) indicates as the least mobile oestrogen compared to $17 \alpha$-ethnyloestradiol (EE2) and 17 $\beta$-oestradiol (E2).

Among the oestrogens, Oestrone (E1) shows the strongest adsorption onto all soils and it shows disparity from most of the previous studies which indicate $17 \alpha$-ethnyloestradiol (EE2) as having the strongest adsorption onto soil. However, the stronger adsorption demonstrated by oestrone (E1) in this study is in agreement with a study reported by Hildebrand [15]. Equal sorptive strength between $17 \alpha$-ethnyloestradiol (EE2) and oestrone (E1) onto the same sorbent have also been reported [20].

\section{E. Relation between Octanol-Water Partition Coefficient $\left(K_{o w}\right)$ and Solid-Water Partition Coefficient $\left(K_{d}\right)$}

From this study, the sorption partition coefficient $\left(K_{d}\right)$ of these oestrogens is accordance with hydrophobicity order obtained (based on $\log K_{o w}$ values). The least hydrophobic oestrogen, 17 $\beta$-oestradiol (E2) shows the weakest adsorption while Oestrone (E1), the most hydrophobic oestrogen, shows the greatest binding to all soils.

The results obtained in this study suggest that the octanol-water partition coefficient $\left(K_{o w}\right)$ is an important parameter in predicting sorption in soils. The experimental of $K_{o w}$ is vital in every study to determine the adsorption potential of any compounds in soil or sediment in order to allow clear interpretation. However, most of the previous study either used default $\log K_{o w}$ given by computational models or values cited in other literatures.

\section{CONCLUSION}

Sorption is the mechanism in determining the mobility and the environmental fate of oestrogens in the environment. In this study, all oestrogens indicate a strong association with organic carbon of the soils. The solid-water partition coefficient $\left(K_{d}\right)$ values obtained in this study shown a good correlation to the organic carbon content as well as the calculated sorption coefficient normalised to organic carbon $\left(K_{o c}\right)$ values. Thus, it can be concluded that organic carbon plays an important factor to bind oestrogens in soils and the $K_{o w}$ is a good predictor of sorption as the affinity of these compounds in soils is strongly dependent to their $K_{o w}$ values.

\section{ACKNOWLEDGMENT}

This study was funded by Ministry of Higher Education (MOHE) of Malaysia (FRGS/RDU 130102). Authors wish to thank to Civil Engineering Department, Faculty of Engineering of Strathclyde University, UK as well as Faculty of Civil Engineering and Earth Resources for their assistance to conduct this study and writing this study.

\section{REFERENCES}

[1] F. Lahnsteiner, B. Berger, M. Kletzl, and T. Weismann, "Effect of $17 \beta$-estradiol on gamete quality and maturation in two salmonid species," Aquatic Toxicology, vol. 79, no. 2, pp. 124-131, 2006.

[2] O. Finlay Moore, P. Hartel, and M. Cabrera, "17 $\beta$-oestradiol and testosterone in soils and runoff from grasslands amended with broiler litter," Journal Environmental Quality, vol. 29, pp. 1604-1611, 2000.

[3] J. Beck, K. Totsche, and I. Kogel-Knabner, "A rapid and efficient determination of natural oestrogens in soils by pressurised liquid 
extraction and gas chromatography-mass spectrometry," Chemosphere, vol. 71, no. 5, pp. 954-960, 2008

[4] L. Shore, D. Correll, and P. Chakraborty, "Relationship of fertilization with chick manure and concentrations of estrogens in small streams," in Animal Waste and the Land-water Interface, K. Steel, Ed., CRC Press Boca Raton, 2003.

[5] E. Peterson, R. Davis, and H. Orndorff, "17/-oestradiol as an indicator of animal waste contamination in mantled karst aquifers," Journal of Environmental Quality, vol. 29, no. 3, pp. 826-834, 2000.

[6] C. Swartz, S. Reddy, M. Benotti, H. Yin, L. Barber, B. Brownawell, and R. Rudel, "Steroid estrogens, nonylphenol ethoxylates metabolites, and other wastewater contaminants in groundwater affected by a residential septic system on Cape Cod," Environmental Science and Technology, vol. 40, no. 16, pp. 4894-4902, 2006.

[7] M. Jurgens, R. Williams, and A. Johnson, "Fate and behaviour of steroid oestrogens in rivers: A scoping study," Environmental Agency R\&D Technical Report, P161, 1999.

[8] K. Lai, K. Johnson, M. Scrimshaw, and J. Lester, "Binding of waterborne steroid estrogens to solid phase river and estuarine systems," Environmental Science and Technology, vol. 34, no. 18, pp. 3890-3894, 2000.

[9] T. Hanselman, D. Graetz, and A. Wilkie, "Manure-borne estrogens as potential environmental contaminants: A review," Environmental Science and Technology, vol. 37, no. 24, pp. 5471-5478, 2003.

[10] Standard test methods for moisture, ash and organic matter of peat and other organic soils, ASTM, 2000.

[11] Standard test method for determining a sorption constant (Koc) for an organic chemical in soil and sediment, ASTM E1195-01, 2001.

[12] Methods of test for soils for civil engineering purposes- Part 1: General requirements and sample preparation, BS 1377-1:1990

[13] B. Horvath, O. Opara-Nadi, and F. Beese, "A simple method for measuring the carbonate content of soils," Soil Science Society of America Journal, vol. 69, no. 4, pp. 1066-1068, 2005.

[14] Guidelines for Testing Chemicals, OECD, 2004.

[15] C. Hildebrand, K. L. Londry, and A. Farenhorst, "Sorption and desorption of three endocrine disrupters in soils," Journal of Environmental Science and Health Part B, vol. 41, no. 6, pp. 907-921, 2006.

[16] G. Ying and R. Kookana, "Degradation of five selected endocrine disrupting chemicals in seawater and marine sediment," Environmental Science and Technology, vol. 37, no. 7, pp. 1256-1260, 2003.
[17] G. Ying, R. Kookana, and P. Dillon, "Sorption and degradation of selected five endocrine disrupting chemicals in aquifer material," Water Research, vol. 37, no. 15, pp. 3785-3791, 2003.

[18] H. Yamamoto and H. Liljestrand, "Partitioning of selected oestrogenic compounds between synthetic membrane vesicles and water: Effects of lipid components," Environmental Science and Technology, vol. 38, no. 4, pp. 1139-1147, 2004.

[19] H. Keenan, A. Sakultantimetha, and S. Bangkedphol, "Environmental fate and partition coefficient of oestrogenic compounds in sewage treatment process," Environmental Research, vol. 106, no. 3, pp. 313-318, 2008.

[20] Z. Yu, B. Xiao, and P. Peng, "Sorption of estrogens to sediments," Environmental Toxicology and Chemistry, vol. 23, no. 3, pp. 531-539, 2004.

E. A. Aziz was born in Johor, Malaysia in 1979 and received the first degree education from National University of Malaysia in B.Eng of Civil Engineering and was graduated with honors in 2001 and later finished the master in 2005 in M.Eng civil engineering (environmental management) Currently, she is working with University Malaysia Pahang as a lecturer. Her research interests are in the environmental fate and transport process of organic compounds in environmental compartments.

W. A. Wan Omar was born in Kelantan, Malaysia in 1988 and received the first degree education from University Malaysia Pahang in B.Eng of civil engineering and was graduated with honors in 2012. She is currently working as a research assistant and at the same time undergoes her master education in Universiti Malaysia Pahang. Her research interest is in environmental management.

N. A. Zainodin was born in Kelantan, Malaysia in 1988 and received the first degree education from University Malaysia Pahang in B.Eng of civil engineering and was graduated with honors in 2012. She is currently working as a research assistant and at the same time undergoes her master education in Universiti Malaysia Pahang. Her research interest is in fate and transport process of organic compounds in environments.

Mir Sujaul Islam was born in Bangladesh and received his the first degree education from there. He was then pursued his master DEGREE and PhD in National University of Malaysia. His research interest is in the water quality assessment and environmental management. 